\title{
The DREAM Protein Negatively Regulates the NMDA Receptor through Interaction with the NR1 Subunit
}

\author{
Ying Zhang, ${ }^{1 \star}$ Ping Su, ${ }^{1 \star}$ Ping Liang, ${ }^{1}$ Tao Liu, ${ }^{2}$ Xu Liu, ${ }^{3}$ Xin-Ying Liu, ${ }^{2}$ Bo Zhang, ${ }^{2}$ Tao Han, ${ }^{1}$ Yan-Bing Zhu, ${ }^{1}$ \\ Dong-Min Yin, ${ }^{1}$ Junfa Li, ${ }^{3}$ Zhuan Zhou, ${ }^{2}$ Ke-Wei Wang, ${ }^{1}$ and Yun Wang ${ }^{1}$ \\ ${ }^{1}$ Neuroscience Research Institute and Department of Neurobiology, Key Laboratory for Neuroscience of Ministry of Education and Health, Peking \\ University, Beijing 100191, China, ${ }^{2}$ Institute of Molecular Medicine and State Key Laboratory of Biomembrane Engineering, Peking University, Beijing \\ 100871, China, and ${ }^{3}$ Department of Neurobiology, Capital Medical University, Beijing 100054, China
}

Glutamate-induced excitotoxicity has been implicated in the etiology of stroke, epilepsy, and neurodegenerative diseases. NMDA receptors (NMDARs) play a pivotal role in excitotoxic injury; however, clinical trials testing NMDAR antagonists as neuroprotectants have been discouraging. The development of novel neuroprotectant molecules is being vigorously pursued. Here, we report that downstream regulatory element antagonist modulator (DREAM) significantly inhibits surface expression of NMDARs and NMDAR-mediated current. Overexpression of DREAM showed neuroprotection against excitotoxic neuronal injury, whereas knockdown of DREAM enhanced NMDA-induced toxicity. DREAM could directly bind to the C0 domain of the NR1 subunit. Although DREAM contains multiple binding sites for the NR1 subunit, residues 21-40 of the $\mathrm{N}$ terminus are the main binding site for the NR1 subunit. Thus, 21-40 residues might relieve the autoinhibition conferred by residues 1-50 and derepress the DREAM core domain by a competitive mechanism. Intriguingly, the cell-permeable TAT-21-40 peptide, constructed according to the critical binding site of DREAM to the NR1 subunit, inhibits NMDARmediated currents in primary cultured hippocampal neurons and has a neuroprotective effect on in vitro neuronal excitotoxic injury and in vivo ischemic brain damage. Moreover, both pretreatment and posttreatment of TAT-21-40 is effective against excitotoxicity. In summary, this work reveals a novel, negative regulator of NMDARs and provides an attractive candidate for the treatment of excitotoxicity-related disease.

\section{Introduction}

Intracellular $\mathrm{Ca}^{2+}$ levels are spatially and temporally highly regulated, and $\mathrm{Ca}^{2+}$-binding proteins serve as effectors to transduce these cellular $\mathrm{Ca}^{2+}$ signals. Downstream regulatory element antagonist modulator (DREAM), which was first identified as a $\mathrm{Ca}^{2+}$-regulated transcriptional repressor, contains four $\mathrm{Ca}^{2+}$ binding $\mathrm{EF}$ hand domains and belongs to the neuronal calcium sensor (NCS) family (Carrión et al., 1999; Burgoyne, 2007). DREAM was named for its ability to block gene expression in its $\mathrm{Ca}^{2+}$-free form via direct binding with the downstream regulatory element sequence in target genes such as preprodynorphin, c-fos, Hrk, and $\mathrm{Na}^{+}$and $\mathrm{Ca}^{2+}$ exchanger NCX3 (Carrión et al., 1999; Sanz et al., 2001; Gomez-Villafuertes et al., 2005). DREAM was also named calsenilin or potassium channel-interacting protein 3 (KChIP3) (Buxbaum et al., 1998; An et al., 2000), suggesting that it has multifunctional properties.

\footnotetext{
Received March 14, 2010; revised April 7, 2010; accepted April 19, 2010.

This work was supported by National Natural Science Foundation of China Grants 30925015, 30900582, 30830044, 30830043, 30728009, and 30770703; Beijing Natural Science Foundation Grant 7092061; National Basic Research 973 Program of China Grants 2007CB512100 and 2006CB500800; and Specialized Research Fund for Doctoral Program of Higher Education Grants 200800011028 and 20060001121.

${ }^{*} Y$.Z. and P.S. contributed equally to this work.

Correspondence should be addressed to Prof. Yun Wang, Neuroscience Research Institute and Department of Neurobiology, Peking University, 38 Xueyuan Road, Beijing 100191, China. E-mail: wangy66@bjmu.edu.cn. DOI:10.1523/JNEUROSCI.1312-10.2010

Copyright $\odot 2010$ the authors $\quad 0270-6474 / 10 / 307575-12 \$ 15.00 / 0$
}

DREAM is preferentially expressed in the CNS, as well as in non-neuronal tissues (Link et al., 2004; D’Andrea et al., 2005; Savignac et al., 2005). Its physiological roles have been gradually revealed. DREAM knock-out mice display a hypoalgesic phenotype, suggesting a critical role for DREAM in pain modulation (Cheng et al., 2002). In addition, emerging evidence supports the role of DREAM in long-term potentiation (Lilliehook et al., 2003), learning, and memory (Alexander et al., 2009; FontánLozano et al., 2009).

NMDA receptors (NMDARs) constitute a major class of ionotropic glutamate receptors and play a key role in synaptic plasticity. Functional NMDARs are heteromultimers formed by the assembly of the NR1 and NR2 subunits. Excessive activation of NMDARs by glutamate mediates neuronal damage in many neurological disorders including ischemia, epilepsy, neurodegenerative disease, and mental disorders (Choi et al., 1988; Sattler and Tymianski, 2001). Thus, NMDARs have long been considered the main target for treatment of excitotoxicity-related neuronal damage, and a variety of antagonists or blockers of NMDARs have been developed. However, the results of clinical trials have been disappointing because of the obvious side effects associated with blocking the physiological roles of NMDARs. Targeting regulatory proteins of NMDARs, therefore, represents an alternative approach to treating NMDAR-mediated excitotoxic injury. Additional elucidation of the regulatory mechanisms of NMDARs is a prerequisite for this strategy. 
Here, we demonstrate that DREAM is a novel negative modulator of NMDARs, which inhibits NMDAR-mediated current and excitotoxic injury. Moreover, the cell-permeable peptide TAT-21-40, constructed according to the critical binding site of DREAM for the NR1 subunit, confers protection against NMDAinduced cell injury in cultured hippocampal neurons and focal ischemic damage in mice by either pretreatment or posttreatment. In summary, our work reveals a novel regulator of NMDARs and provides important evidence for the emerging role of DREAM in learning and memory (Alexander et al., 2009; Fontán-Lozano et al., 2009). The therapeutic potential of the TAT-21-40 peptide may also extend to other pathologies with an excitotoxic component, including hypoxic, ischemic, and traumatic brain damage and neuronal death arising from epileptic seizures and neurodegenerative diseases.

\section{Materials and Methods}

Plasmids and chemicals. Plasmids for pCDNA3.1(+)-NR1-1a and PRK5NR2B were kindly provided by David R. Lynch (Department of Neurology, University of Pennsylvania, Philadelphia, PA). GFP-DREAM plasmids were constructed by PCR from rat brain cDNA and subcloned into the XhoI-HindIII site of the pEGFP-N1 vector (Clontech) or the XhoI-EcoRI site of the pEGFP-C2 vector (Clontech). Prokaryotic expression constructs encoding different fragments of the NR1-1a C terminus were generated by PCR from pCNDA3.1(+)-NR1-1a and subcloned into the EcoRI-XhoI site of the PGEX-5x-1 vector (Clontech) or the EcoRI-HindIII site of the pet28a(+) vector (Novagen). The different DREAM prokaryotic expression vectors were generated by PCR from rat brain cDNA and subcloned into the EcoRI-XhoI site of the PGEX-5x-1 vector or the EcoRI-HindIII site of the pet $28 \mathrm{a}(+)$ vector. For oocyte expression, cDNA constructs of NR1-1a, NR2B, and DREAM were subcloned into the pBluescript KSM vector (Stratagene). The EF hand II, III, IV mutant DREAM vector was constructed by the following mutations: D137A, D139A, D175A, N177A, D223A, and D225A, using the QuickChange site-directed mutagenesis kit (Stratagene). The sequence of the plasmids and mutations was confirmed by DNA sequencing (Shanghai Shenggong Bio).

Monoclonal glutathione $S$-transferase (GST) and $\mathrm{His}_{6}$ primary antibodies were obtained from Applygen Beijing. Monoclonal green fluorescent protein (GFP) antibody and polyclonal NR1, NR2B, glutamate receptor 1 (GluR1), and DREAM antibodies were purchased from Santa Cruz Biotechnology. Monoclonal DREAM antibody was from Millipore. Monoclonal $\beta$-actin and N-cadherin antibodies were from Sigma-Aldrich. HRP-labeled secondary antibodies were from Jackson ImmunoResearch. Trypsin, glutamine, cytosine-D-arabinofuranoside (Ara-C), poly-D-lysine, Hoechst 33342, propidium iodide (PI), NMDA, glutamate, glycine, ketamine, and dizocilpine (MK801) were from Sigma-Aldrich. All restriction enzymes were purchased from New England Biolabs, and all cell culture media were from Invitrogen. TAT-fusion peptides were synthesized by GL Biochem Shanghai.

Cell culture and transfection. HEK 293 and CHO cells were maintained in DMEM and F12 medium, respectively, plus 10\% fetal bovine serum (HyClone) at $37^{\circ} \mathrm{C}$ in $5 \% \mathrm{CO}_{2}$. After passaging for $16-24 \mathrm{~h}$, plasmid transfection was performed with jetPEI Transfection reagent (Qbiogene). In brief, plasmids and transfection reagent ( $2 \mu \mathrm{l}$ of jetPEI per microgram of DNA) were diluted with $150 \mathrm{~mm} \mathrm{NaCl}$. They were then mixed together followed by incubation for $15 \mathrm{~min}$ at room temperature. Finally, the mixture was added to the medium in the presence of $500 \mu \mathrm{M}$ ketamine to prevent NMDAR activation. Cells were used $24 \mathrm{~h}$ after transfection.

Primary culture of hippocampal neurons. Primary hippocampal neurons were derived from embryonic day 18 Sprague Dawley rats. Briefly, hippocampi were mechanically separated in ice-cold $\mathrm{Ca}^{2+}-$ and $\mathrm{Mg}^{2+}$ -

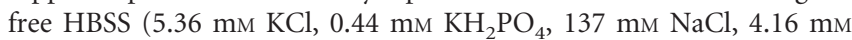
$\mathrm{NaHCO}_{3}, 0.34 \mathrm{~mm} \mathrm{Na} \mathrm{HPO}_{4} \cdot 2 \mathrm{H}_{2} \mathrm{O}, 5 \mathrm{~mm}$ glucose, 1 mm sodium pyruvate, $10 \mathrm{~mm}$ HEPES, and $0.001 \%$ phenol red, $\mathrm{pH}$ 7.2-7.4). Hippocampal cells were dissociated by trypsinization $(0.25 \%$ trypsin and $0.05 \%$ EDTA in $\mathrm{Ca}^{2+}$ - and $\mathrm{Mg}^{2+}$-free $\mathrm{HBSS}$ ) at $37^{\circ} \mathrm{C}$ for $30 \mathrm{~min}$, followed by gentle trituration in plating medium (DMEM supplemented with $10 \%$ fetal bovine serum). Cells were seeded onto poly-D-lysine-coated wells at a density of $1 \times 10^{5}$ cells $/ \mathrm{cm}^{2}$ and incubated at $37^{\circ} \mathrm{C}$ in $5 \% \mathrm{CO}_{2}$ atmosphere. After 6 h, cultures were replaced with Neurobasal medium supplemented with B27 and $0.5 \mathrm{~mm}$ glutamine, and then one-half was replaced twice every week. To inhibit the growth of glial cells, $10 \mu \mathrm{M}$ Ara- $\mathrm{C}$ was added to the culture at day 3 and maintained until the end of the experiments. Cultures were used after $12 \mathrm{~d}$ in vitro.

Short interfering RNA. The sequence of DREAM short interfering RNA (siRNA) was as follows: 5' -CCGAGGCUUCAAGAACGAA-3'. Control siRNA was 5'-UUCUCCGAACGUGUCACGU-3', which should not knockdown any known proteins. The above siRNA molecules were chemically synthesized by Shanghai Genechem Company.

Generation of adenoviral vectors and neuronal infection. Recombinant adenovirus coexpressing GFP and DREAM was constructed using the AdEasy adenoviral vector system (Invitrogen). Rat DREAM cDNA was cloned into the shuttle vector, which was linearized with PmeI and cotransformed into BJ5183 together with pAdEasy-1. Transformants were selected on kanamycin-positive media, and recombinants were subsequently identified by restriction digest. Purified recombinant adenoviral plasmid DNA was then linearized by PacI to expose its inverted terminal repeats and transfected into HEK 293 cells. The recombinant viruses were purified by $\mathrm{CsCl}$ step gradients and stored at $-80^{\circ} \mathrm{C}$. Primary neurons on days $10-12$ in vitro were exposed to virus for $6 \mathrm{~h}$ at a multiplicity of infection of 100. Experiments were performed $48-72 \mathrm{~h}$ after infection.

In vitro excitotoxicity model. For studies involving NMDAR-induced cell injury, delayed toxicity was measured in hippocampal neurons. The culture media were removed, and the cells were challenged with $100 \mu \mathrm{M}$ NMDA (plus $10 \mu \mathrm{M}$ glycine) in $\mathrm{Mg}^{2+}$-free Krebs'-Ringer's buffer for $1 \mathrm{~h}$. The NMDA solution was then replaced with Neurobasal medium (without phenol red), and the cultures were returned to the incubator until the assay of cell injury.

Oxygen and glucose deprivation model. Neurons were washed three times and incubated with deoxygenated glucose-free bicarbonate solution in an anaerobic chamber (model 1025; Thermo Fisher Scientific) with an atmosphere of $85 \% \mathrm{~N}_{2}, 10 \% \mathrm{H}_{2}$, and $5 \% \mathrm{CO}_{2}$ at $37^{\circ} \mathrm{C}$. In the control group, neurons were washed with normal glucose-containing bicarbonate solution and incubated in the standard culture environment. After $30 \mathrm{~min}$, oxygen-glucose deprivation (OGD) was terminated to avoid serious injury to the neurons by washing three times with oxygenated glucose-containing $(20 \mathrm{~mm})$ bicarbonate solution. The cultures were then replaced with normal medium and returned to the normal incubator until the assay of cell injury.

Western blot analysis. Cell cultures were washed twice with ice-cold PBS (137 mm NaCl, $2.7 \mathrm{~mm} \mathrm{KCl,} 10 \mathrm{~mm} \mathrm{Na}_{2} \mathrm{HPO}_{4}, 2 \mathrm{~mm} \mathrm{KH}_{2} \mathrm{PO}_{4}$ ) and lysed in ice-cold lysis buffer (50 mu Tris- $\mathrm{HCl}, \mathrm{pH} 7.4,150 \mathrm{~mm} \mathrm{NaCl}, 1.5$ mм $\mathrm{MgCl}_{2}, 10 \%$ glycerol, $1 \%$ Triton X-100, 5 mm EGTA, $1 \mu \mathrm{g} / \mathrm{ml}$ leupeptin, $1 \mathrm{~mm}$ PMSF, $1 \mathrm{mM} \mathrm{Na}_{3} \mathrm{VO}_{4}, 10 \mathrm{~mm} \mathrm{NaF}$, and proteinase inhibitor mixture). The lysates were centrifuged at $12,000 \times g$ for $5 \mathrm{~min}$ to yield the total protein extract in the supernatant. The concentration of protein was measured with a BCA assay kit (Pierce). Equal amounts of samples (50 $\mu \mathrm{g}$ ) were denatured and subjected to $10 \%$ SDS-PAGE. After separation, proteins were transferred to nitrocellulose membranes (Bio-Rad Laboratories). The membranes were blocked with $5 \%$ nonfat milk in TBST (25 mm Tris- $\mathrm{HCl}$, pH 7.4, $137 \mathrm{~mm} \mathrm{NaCl}, 2.7 \mathrm{~mm} \mathrm{KCl}$, and 0.05\% Tween 20) for $1 \mathrm{~h}$ at room temperature and incubated with primary antibody overnight at $4^{\circ} \mathrm{C}$. After washing three times with TBST, the membranes were incubated with secondary antibody for $1 \mathrm{~h}$ at room temperature, and then washed again and finally developed with ECL solutions (Santa Cruz Biotechnology). For multiple detections with different antibodies, blots were first stripped with stripping buffer $(62.5 \mathrm{~mm}$ Tris- $\mathrm{HCl}, \mathrm{pH} 6.8$, $20 \mathrm{~mm}$ dithiothreitol, and $1 \%$ SDS) for $20-30 \mathrm{~min}$ at $55^{\circ} \mathrm{C}$ and washed twice with TBST, followed by blocking and incubation with a new primary antibody. The immunoreactive bands were scanned and analyzed quantitatively by densitometry with TotalLab software (GE Healthcare).

Coimmunoprecipitation experiment. Rat hippocampi were immediately homogenized in ice-cold lysis buffer as described above. After being rotated at $4^{\circ} \mathrm{C}$ for $1 \mathrm{~h}$, the homogenates were centrifuged at $12,000 \times$ $g$ for 5 min to yield the total protein extract in the supernatant. Protein extract from tissue or cell cultures was incubated with either 
A

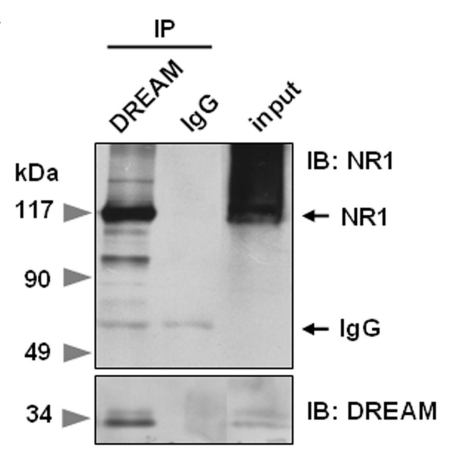

C
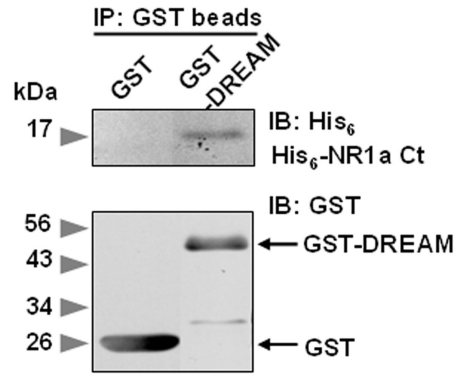

E

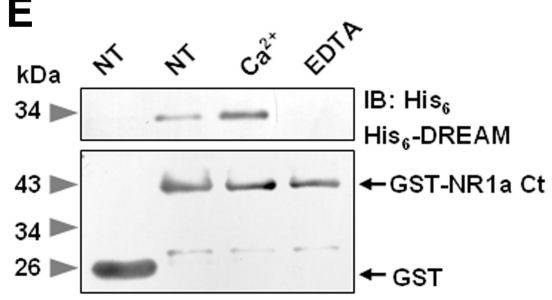

B

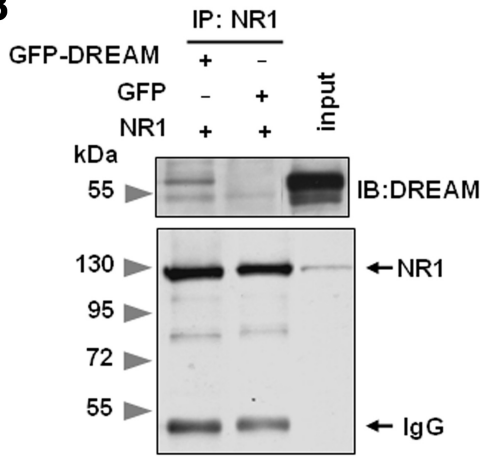

D
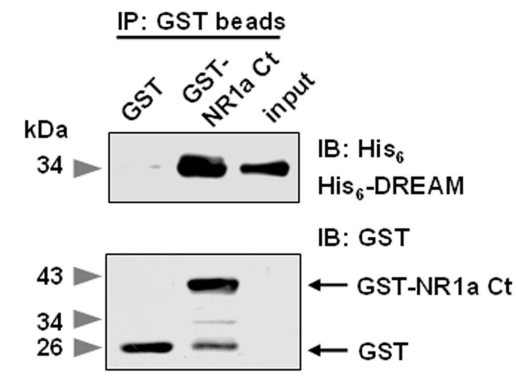

$\mathbf{F}$

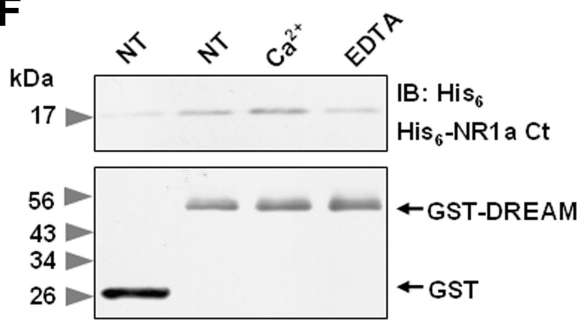

Figure 1. Association of DREAM with the NR1 subunit and effect of $\mathrm{Ca}^{2+}$ on the DREAM-NR1 interaction. $A, B$, Coimmunoprecipitation (IP) studies of DREAM and the NR1 subunit in rat hippocampus extracts $(\boldsymbol{A})$ and in HEK 293 cells transfected with pEGFP-C2 or pEGFP-C2-DREAM and pCDNA3-NR1-1a plasmids (B). C, GST-DREAM precipitated His $s_{6}-N R 1 a$ Ct (His 6 -NR1-1a C termi-

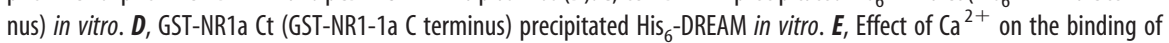
GST-NR1a Ct to His 6 -DREAM. Addition of $100 \mu \mathrm{Mad}^{2+}$ in the reaction buffer enhanced the binding, whereas addition of $10 \mathrm{~mm}$ EDTA attenuated that. $\boldsymbol{F}$, Effect of $\mathrm{Ca}^{2+}$ on the binding of GST-DREAM to His 6 -NR1a Ct. NT, No treatment.

DREAM or NR1 antibody $(1: 100)$ at $4^{\circ} \mathrm{C}$ for $3 \mathrm{~h}$. Protein A-Sepharose CL-4B resin (GE Healthcare) was added to the samples, and the incubation continued for another $12 \mathrm{~h}$. Subsequently, the samples were washed six times with TBS containing $0.1 \%$ Triton X-100 and subjected to SDS-PAGE.

GST pull-down assay. GST- or $\mathrm{His}_{6}$-fusion proteins were expressed in the BL21 Escherichia coli strain and purified according to the manufacturer's instructions. For binding assays, GST or GST-fusion protein was immobilized on glutathione-Sepharose resin (GE Healthcare). $\mathrm{His}_{6}$ fusion protein was purified using Ni-nitrilotriacetic acid magnetic beads (QIAGEN). The protein extracts from tissue or purified $\mathrm{His}_{6}$-fusion protein was then incubated with the immobilized GST or GST-fusion protein for $1 \mathrm{~h}$ at $4^{\circ} \mathrm{C}$, washed, and subjected to SDS-PAGE.

Surface biotinylation assay. Cell cultures were washed twice with icecold PBS and incubated for $30 \mathrm{~min}$ at $4^{\circ} \mathrm{C}$ with EZ-Link Sulfo-NHS-SSbiotin $(1 \mathrm{mg} / \mathrm{ml}$; Pierce) to biotinylate surface proteins. Excess biotin reagent was quenched and removed by washing the cells with PBS containing $100 \mathrm{~mm}$ glycine. Cells were lysed with lysis buffer $(137 \mathrm{~mm}$ $\mathrm{NaCl}, 2.7 \mathrm{~mm} \mathrm{KCl}, 10 \mathrm{~mm} \mathrm{Na} \mathrm{HPO}_{4}, 2 \mathrm{~mm} \mathrm{KH} \mathrm{PO}_{4}, 1 \%$ Triton $\mathrm{X}-100,0.1 \%$ SDS, and proteinase inhibitor mixture, $\mathrm{pH} 7.4)$. The lysates were centrifuged at $12,000 \times g$ for 5 min to yield the protein extract in the supernatant. Then protein extracts were incubated with UltraLink Plus immobilized streptavidin beads (Pierce) for $2 \mathrm{~h}$ at $4^{\circ} \mathrm{C}$ to capture biotinylated surface protein. After being washed with lysis buffer five times, bound proteins were eluted by boiling for 5 min with loading buffer and subjected to SDS-PAGE.

Hoechst 33342 and PI staining. Cultures were rinsed with PBS twice and incubated with 1 $\mu \mathrm{g} / \mathrm{ml}$ PI or double labeling of Hoechst 33342 $(2 \mu \mathrm{g} / \mathrm{ml})$ and PI for $10 \mathrm{~min}$, and then rinsed three times with PBS. Images were immediately collected by a fluorescent microscope (Leica) equipped with a cooled CCD digital camera. For quantitative analysis, at least six fields were imaged for each sample.

Lactate dehydrogenase assay. Lactate dehydrogenase $(\mathrm{LDH})$ release in the culture medium was measured using the LDH assay kit (Promega). Medium (50 $\mu \mathrm{l})$ was transferred from culture wells to 96-well plates, mixed with $50 \mu \mathrm{l}$ of reaction solution, and incubated for 30 min at room temperature. Stop solution was then added, and the optical density was measured at $490 \mathrm{~nm}$ using a microplate reader (Bio-Rad).

Two-electrode voltage-clamp recordings in Xenopus oocytes. Stage V or VI Xenopus oocytes were selected and injected with NR1-1a, NR2B, and DREAM cRNAs using a microinjector (Drummond Scientific). cRNAs were in vitro transcribed using the T3 mMESSAGE Machine kit (Ambion) after linearization of the pBluescript KSM construct with NotI enzyme. The total amount of cRNA injected was 7.5-15 ng, and NR1-1a, NR2B, and DREAM cRNAs were injected at a ratio of 1:2:2. One to $2 \mathrm{~d}$ after injection, oocytes were impaled with two microelectrodes $(0.5-1.0 \mathrm{M} \Omega$ ) filled with 3 $\mathrm{M} \mathrm{KCl}$ in a $40 \mu \mathrm{l}$ recording chamber. Oocytes were perfused with a constant stream of $\mathrm{Ba}^{2+}$ Ringer's solution (115 mM NaCl, $2.5 \mathrm{~mm} \mathrm{KCl}$, $1.8 \mathrm{~mm} \mathrm{BaCl}_{2}, 10 \mathrm{~mm}$ HEPES, $\mathrm{pH}$ 7.2) at 23$25^{\circ} \mathrm{C}$. The oocyte membrane was voltageclamped at $-70 \mathrm{mV}$, and currents were recorded using a GeneClamp 500 amplifier (Molecular Devices). The data were acquired using Pulse software (HEKA), digitized at 1.0 $\mathrm{kHz}$ using an ITC-16 (InstruTECH Corporation), and analyzed using PulseFit or OriginLab Origin 6.1.

Recordings of NMDA-induced currents in hippocampal neurons. Wholecell recordings were made on primary cultured hippocampal neurons on days $10-12$ in vitro. Patch electrodes were $\sim 3-5 \mathrm{M} \Omega$. The intracellular electrode solution contained the following: $140 \mathrm{~mm} \mathrm{CsCl}, 2.5 \mathrm{~mm}$ EGTA, $2 \mathrm{~mm} \mathrm{MgCl}_{2}, 10 \mathrm{~mm}$ HEPES, $2 \mathrm{~mm}$ tetraethylammonium, and $4 \mathrm{~mm}$ $\mathrm{Na}_{2} \mathrm{ATP}$, with $\mathrm{pH}$ adjusted to 7.3. The extracellular solution was $140 \mathrm{~mm}$ $\mathrm{NaCl}, 1.3 \mathrm{~mm} \mathrm{CaCl}_{2}, 5 \mathrm{~mm} \mathrm{KCl}, 25 \mathrm{~mm}$ HEPES, $33 \mathrm{~mm}$ glucose, and $0.0005 \mathrm{~mm}$ TTX, with $\mathrm{pH}$ adjusted to 7.4. A perfusion system (RCP-2B; INBIO) with a fast exchange time $(\sim 100 \mathrm{~ms})$ for electronic switching between seven channels was used to change external medium. All experiments were performed at room temperature $\left(22-25^{\circ} \mathrm{C}\right)$. Currents were recorded using an EPC10/2 amplifier and Pulse software (HEKA Elektronik). The data were analyzed using Igor software (Wavemetrics).

Permanent focal cerebral ischemia and TAT-fusion peptide administration. $\mathrm{BALB} / \mathrm{c}$ mice (male; 8-10 weeks of age; $18-22 \mathrm{~g}$ ) were allowed ad libitum access to water but deprived of food for $12 \mathrm{~h}$ before surgery. Mice were anesthetized with pentobarbital sodium $(0.06 \mathrm{~g} / \mathrm{kg})$ by intraperitoneal injection. Focal ischemia was induced with minor modifications of Tamura's middle cerebral artery occlusion (MCAO) model (Mayanagi et al., 2008). Briefly, the left common and external carotid arteries were exposed through a ventral midline neck incision and were ligated, respectively. A monofilament with blunt tip was inserted into the internal carotid artery to a point $\sim 12 \mathrm{~mm}$ distal to the carotid bifurcation until 
a mild resistance was felt, thereby occluding the origins of the anterior and middle cerebral arteries. During the surgery, body temperature was maintained by using a heating lamp. Mice were placed in a postoperative cage and kept warm until neurological testing and killing after MCAO for $6 \mathrm{~h}$.

The Tat-21-40 $(2 \mu \mathrm{g} / \mu \mathrm{l})$ or scramble-Tat (control) peptide in $2.5 \mu \mathrm{l}$ of saline was administrated to the mice $20 \mathrm{~min}$ before MCAO or 20 min after MCAO through left lateral ventrical infusion (anteroposterior, $0.5 \mathrm{~mm}$; lateral, 1 $\mathrm{mm}$; and depth, $3.5 \mathrm{~mm}$ from the bregma).

Neurological deficit measurement. Mice neurological deficits were assessed $6 \mathrm{~h}$ after MCAO in a blinded manner, according to the methods described by Rodriguez et al. (2005). It involves an initial phase of undisturbed observation (hypomobility, lateralized posture, flattened posture, hunched back, piloerection, ataxic gait, circling, tremors, twitches, convulsions, and respiratory distress) and a later manipulative phase (passivity, hyperreactivity, irritability, ptosis, urination, decreased body tone, forelimb flexion, decreased muscle strength, body rotation, and motor incoordination). Based on the results of the above observation, neurological behavior was scored on a 10-point scale. In all cases, where criteria for the precise grade were not met, the nearest appropriate number was used: 1,3, 5, 7, and 9.

Evaluation of ischemic infarct and edema. Mice were killed after neurological testing and the brain was quickly removed and cut into 2-mm-thick coronal sections. Brain sections were incubated for $20 \mathrm{~min}$ in a solution of $0.5 \%$ 2,3,5-triphenyltetrazolium chloride (TTC) in $0.01 \mathrm{M} \mathrm{PBS}$ at $37^{\circ} \mathrm{C}$, and then the slices were photographed by a scanner. These images were analyzed using Image Pro Plus 6.0 (Media Cybernetics) according to Eric's ischemic area evaluation procedure (Wexler et al., 2002). Edema was calculated using the equation: $E=$ $\left(\sum \mathrm{VL}-\sum \mathrm{VR}\right) /\left(\sum \mathrm{VL}+\sum \mathrm{VR}\right)^{\star} 100 \%$, where $\sum \mathrm{VL}$ and $\sum \mathrm{VR}$ are the volume of left and right hemisphere volume, respectively. Background is also involved in evaluation and was calculated using the following equation: $B=\sum \mathrm{VS} /$ $\sum \mathrm{VT}^{\star} 100 \%$, where $\sum \mathrm{VS}$ is the volume of the unstained white matter in sham group and $\sum \mathrm{VT}$ is the total brain volume. To account for the effect of edema and background, infarct size was expressed as a percentage of the total brain by using the following equation: $I=$ $\left[\sum \mathrm{VI}^{\star}(1-E) / \sum \mathrm{VT}^{*}(1-B)\right]^{*} 100 \%$, where $\sum \mathrm{VI}$ is the volume of TTC unstained tissue.

Statistical analysis. Values are expressed as the means \pm SEM and were obtained from at least three independent experiments. Statistical analysis of the results was performed using Prism 4.0 software. A value of $p<0.05$ was considered significant.

\section{Results}

\section{Association between DREAM and the NR1 subunit}

First, we performed coimmunoprecipitation (co-IP) studies to test whether there was an interaction between DREAM and the NR1 subunit, the obligatory subunit of NMDARs. DREAM antibody, but not normal rabbit IgG, immunoprecipitated endogenous NR1 and DREAM protein present in rat hippocampal tissue (Fig. $1 A$ ). As a control, no precipitation of GluR1 by DREAM

$\mathbf{F}$ kD
B
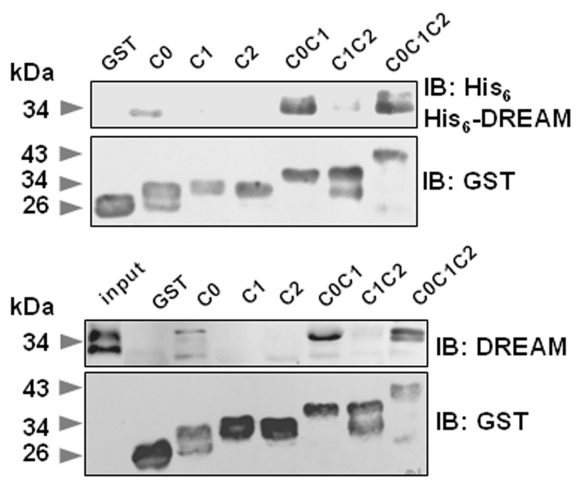

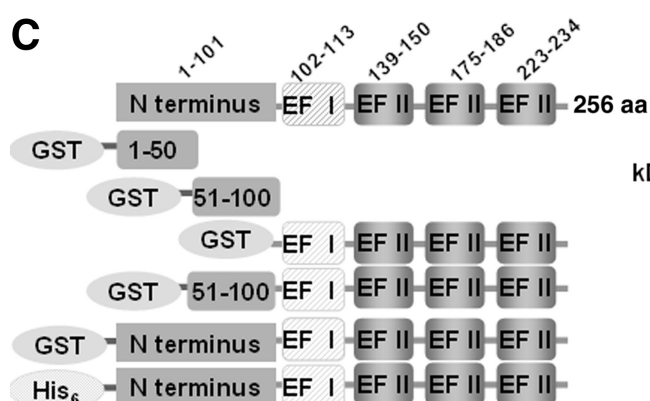

D

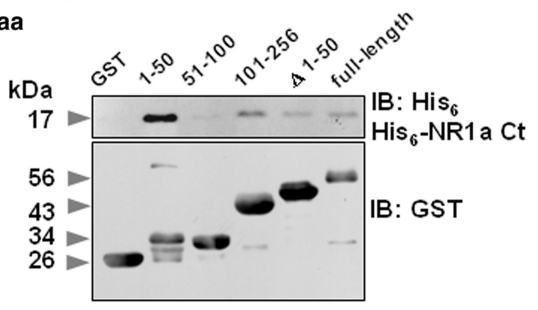

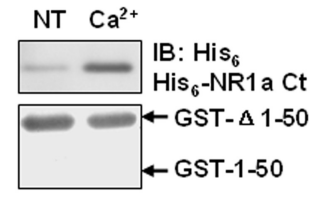

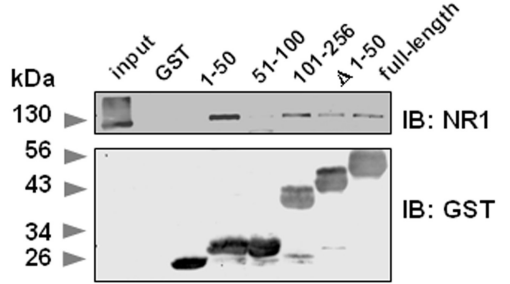

Figure 2. Identification of the binding sites between DREAM and NR1. $\boldsymbol{A}$, Schematic representation of the plasmid construction of GST- and $\mathrm{His}_{6}$-fusion protein containing different domains of the NR1-1a C terminus. B, GST-CO, COC1, and COC1C2 precipitated t. The bands detected by the GST antibody represent the loading amount. C, Schematic representation of the plasmid construcength precipitated both $\mathrm{His}_{6}$-NR1a Ct (top) and endogenous NR1 present in hippocampal tissue (bottom), whereas GST and GST-51-100 $\mathrm{Ca}^{2+}$ sensitivity of the binding between $\Delta 1-50$ DREAM and NR1a C terminus, although it could not cancel their binding. NT, No treatment; EFmu DREAM, EF hand mutant of DREAM.

antibody was detected in hippocampal preparations (supplemental Fig. S1 A, available at www.jneurosci.org as supplemental material). In the reciprocal co-IP studies in HEK 293 cells transfected with GFP or GFP-DREAM and NR1-1a (NR1a) plasmids, NR1 antibody immunoprecipitated DREAM along with the NR1 subunit (Fig. $1 B$ ). This finding indicated that the association between DREAM and NR1 occurred in the absence of the assembly of the NR1 with NR2 subunits. Together, the above results showed that DREAM and the NR1 subunit could form a complex in vivo. The possibility of an indirect interaction involving an accessory binding protein, however, cannot be excluded.

To investigate whether there was a direct interaction between DREAM and the NR1 subunit, we performed GST pull-down 


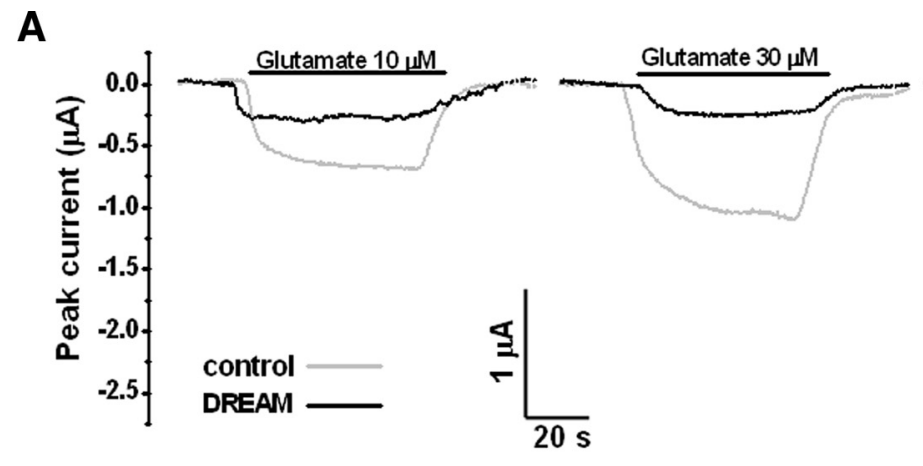

B

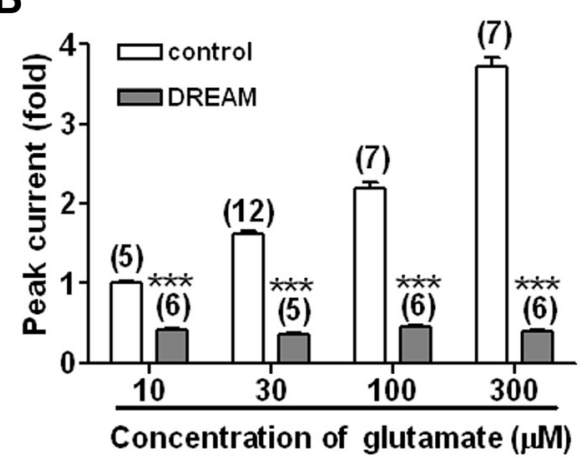

C

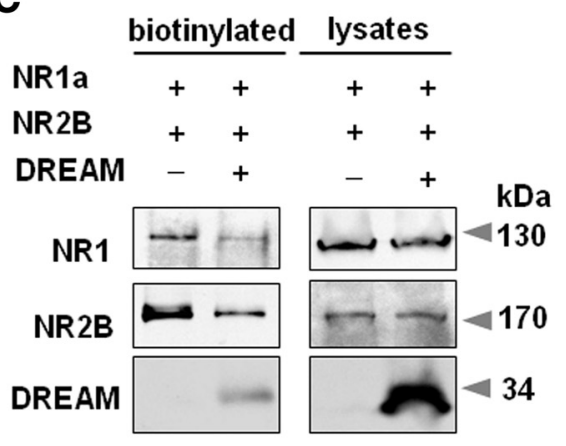

Glutamate $100 \mu \mathrm{M}$

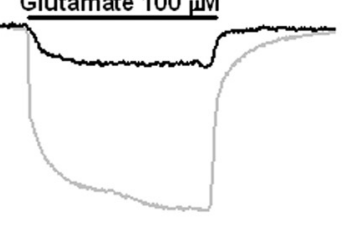

Glutamate $300 \mu \mathrm{M}$

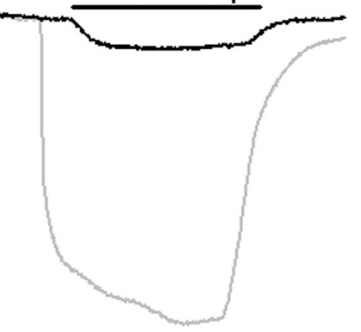

D

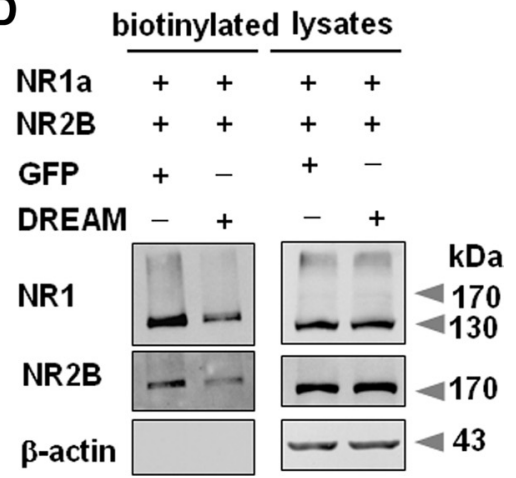

Figure 3. Inhibition of NMDAR-mediated current and NMDAR surface expression by coexpression of DREAM. $\boldsymbol{A}$, Inhibition of the NMDAR-mediated current by coexpression of DREAM. Glutamateevoked whole-cell currents were recorded from Xenopus 0ocytes expressing NR2B-containing NMDARs alone (gray traces) or together with DREAM (black traces). The bars indicate the duration of the application of agonists with different concentrations $\left(10,30,100\right.$, and $300 \mu \mathrm{m} \mathrm{L}$-glutamate, respectively, plus $100 \mu \mathrm{m}$ glycine). $\boldsymbol{B}$, Quantitative analysis of the peak current responses in $\boldsymbol{A}$. ${ }^{* * *} p<$ 0.001, two-way ANOVA followed by Bonferroni's posttests. Error bars indicate SEM. C, Coexpression of DREAM suppressed the surface expression of NR1 and NR2B subunits in 0ocytes. Protein surface expression was detected by surface biotinylation assay. D, Coexpression of DREAM inhibited the surface expression of NR1 and NR2B subunits in CH0 cells transfected pEGFP-N1-DREAM along with pCDNA3-NR1-1a and PRK5-NR2B plasmids compared with control group.

assays. The NR1 subunit arises from one gene, with eight functional splicing variants, and NR1a is the major isoform. According to the topological structure of NR1, only its C terminus is intracellular. Combined with previous studies, we speculated that the possible binding site of DREAM to NR1 was located in the C terminus of NR1. As expected, GST-DREAM precipitated $\mathrm{His}_{6}$ NR1a Ct (NR1-1a C terminus) (Fig. 1C). Conversely, GST-NR1a Ct precipitated $\mathrm{His}_{6}$-DREAM (Fig. 1D). As a negative control, GST did not bind to the corresponding $\mathrm{His}_{6}$-fusion proteins. These data showed a direct interaction between DREAM and the NRla C terminus.

Given the $\mathrm{Ca}^{2+}$ binding properties of DREAM, the regulation of the DREAM-NR1 interaction by $\mathrm{Ca}^{2+}$ was determined. The addition of $100 \mu \mathrm{M} \mathrm{Ca}^{2+}$ to the reaction medium enhanced binding, whereas chelation of $\mathrm{Ca}^{2+}$ by $10 \mathrm{~mm}$ EDTA reduced binding in either the GST-NR1a Ct pull-down His $_{6}$-DREAM assay (Fig. $1 E$ ) or the GST-DREAM pull-down $\mathrm{His}_{6}$-NR1a Ct assay (Fig. $1 F)$. These findings showed that the DREAM-NR1 interaction was sensitive to $\mathrm{Ca}^{2+}$.

Like many other NR1-interacting proteins, $\mathrm{Ca}^{2+} /$ calmodulindependent protein kinase II (CaMKII) (Leonard et al., 1999), $\alpha$-actinin (Wyszynski et al., 1997), tubulin (van Rossum et al., 1999), and spectrin (Wechsler and Teichberg, 1998) also interact with NR2 subunits. Thus, we could not rule out the possibility of the interaction between DREAM and NR2 subunits. Co-IP studies in hippocampal extracts demonstrated the association of DREAM and NR2B subunits (supplemental Fig. S1 B, available at www.jneurosci.org as supplemental material). Direct binding of NR2A or NR2B C terminus with DREAM was also detected by the GST-pull-down assays (supplemental Fig. S1C, available at www.jneurosci.org as supplemental material). As different NR2 subunits confer distinct electrophysiological and pharmacological properties on the NMDARs and couple with different signaling pathways, we focused on the interaction of DREAM and NR1 subunit in this study.

\section{Identification of the binding site between DREAM and the NR1 subunit}

Figure 1 shows a direct interaction between DREAM and the NR1a C terminus; now we further identified the binding sites. The NR1a C terminus is composed of C0, C1, and C2 cassettes. To identify the binding site present in the NRla $\mathrm{C}$ terminus, prokaryotic expression vectors encoding different domains of the NR1a C terminus were constructed (Fig. 2A). Purified GST-C0, $\mathrm{C} 0 \mathrm{C} 1$, and $\mathrm{C} 0 \mathrm{C} 1 \mathrm{C} 2$ fusion proteins bound not only to $\mathrm{His}_{6}$ DREAM (Fig. $2 B$, top) but also to endogenous DREAM in hippocampal tissue (Fig. 2 B, bottom), whereas GST, GST-C1, C2, and $\mathrm{C} 1 \mathrm{C} 2$ did not. All blots were probed in parallel with a GST antibody to confirm equivalent protein loading. Altogether, both the in vitro and one-half in vitro GST pull-down assays revealed that C0 domain was not only necessary but also sufficient for binding between DREAM and the NR1a C terminus.

Similarly, to determine the binding site of DREAM, various GST-fusion proteins encoding DREAM-1-50, 51-100, 101-256, $\Delta 1-50$, and full-length DREAM were prepared (Fig. $2 C$ ). Both in vitro and one-half in vitro GST pull-down assays demonstrated that almost all of these GST-fusion proteins, except the DREAM51-100 fragment, have the ability to bind the NR1a C terminus (Fig. $2 D$, top) and the endogenous NR1 subunit in hippocampus extracts (Fig. 2D, bottom). Therefore, it appeared that DREAM 
contains multiple binding sites for the NR1 subunit. The strongest binding site, however, should be located in the DREAM-1-50 residues of the $\mathrm{N}$ terminus.

Furthermore, the region of the DREAM protein responsible for the $\mathrm{Ca}^{2+}$ sensitivity was determined. Both DREAM-1-50 and $\Delta$ 1-50 fragments were able to bind to the NRla C terminus. However, the binding of the latter was sensitive to $\mathrm{Ca}^{2+}$, whereas the former lacked this sensitivity (Fig. 2E). And the role of the EF hand domains in $\mathrm{Ca}^{2+}$ sensitivity was investigated. Mutation of critical sites in EF hands II, III, and IV completely abolished the $\mathrm{Ca}^{2+}$ binding capacity of DREAM, producing a $\mathrm{Ca}^{2+}$-insensitive mutant of DREAM $\Delta 1-50$ (EFmu DREAM $\Delta 1-50$ ). EFmu DREAM $\Delta 1-50$ still bound to NR1, but this binding was no longer regulated by $\mathrm{Ca}^{2+}$ (Fig. $2 \mathrm{~F}$ ). Together, these data showed that the $\mathrm{Ca}^{2+}$ sensitivity of DREAMNR1 interaction depends on the EF hand domains of DREAM.

\section{Effect of DREAM coexpression on \\ NMDAR-mediated current}

To investigate the direct effect of DREAM on NMDA channels, we recorded NMDARmediated currents in Xenopus oocytes expressing NR2B-containing NMDARs alone or together with DREAM using twoelectrode voltage clamp. In the absence of DREAM, the peak currents of NMDA channels activated by glutamate ranging from 10 to $300 \mu \mathrm{M}$ (plus $100 \mu \mathrm{M}$ glycine) showed the dose-dependent increasing from one to approximately fourfold. In contrast, coexpression of DREAM attenuated glutamateinduced current to a constant low level (Fig. $3 A, B)$. As this current could be abolished completely by APV, an NMDA receptorspecific antagonist, in both groups (supplemental Fig. S2 $A, B, D$, available at www. jneurosci.org as supplemental material) and no endogenous NMDA current (supplemental Fig. S2C, available at www.jneurosci. org as supplemental material) or NR1 and NR2B protein (supplemental Fig. S3, available at www.jneurosci.org as supplemental material) were detected in uninjected oocytes, we speculated that the remaining NMDARs in the presence of DREAM were functional. Together, these results indicated that coexpression of DREAM inhibited the current response of NR2B-containing NMDARs.

To further investigate the mechanisms of the inhibitory effect of DREAM on NMDAR-mediated current, surface expression levels of NMDARs in Xenopus oocytes were examined using a biotinylation assay. Coexpression of DREAM greatly decreased the surface expression of NR1 and NR2B with no change in total receptor amounts (Fig. 3C). It is worth noting that surface expression of DREAM in Xenopus oocytes was detected. Following studies in hippocampal neurons also revealed the presence of DREAM on the plasma membrane (see Fig. $5 F$ ). Parallel experi-
B

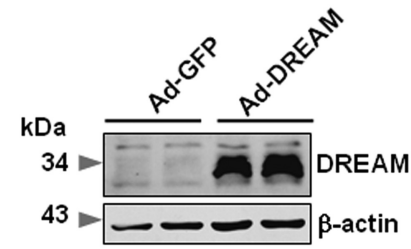

D

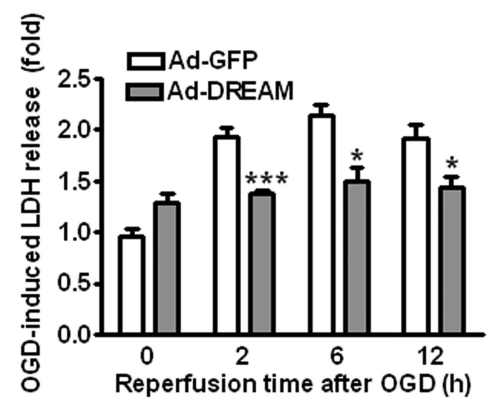

$\mathbf{F}$
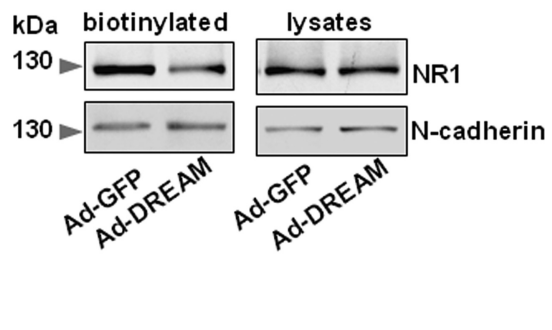

Figure 4. Neuroprotective effect of DREAM overexpression in primary cultured hippocampal neurons. $\boldsymbol{A}$, Coexpression of fullDREAM in hippocampal neurons detected by Western blot analysis. C, Overexpression of DREAM decreased NMDA-induced LDH in hippocampal neurons. ${ }^{*} p<0.05,{ }^{* *} p<0.01,{ }^{* * *} p<0.001 ; n=4$; unpaired $t$ test. $D$, Overexpression of DREAM EM. $\boldsymbol{E}$, Representative images of $\mathrm{PI}$ staining in hippocampal neurons after $0 \mathrm{GD}$ or control treatment for $30 \mathrm{~min}$ and reperfusion for $24 \mathrm{~h}$. Overexpression of DREAM reduced the number of PI-positive cells. $\boldsymbol{F}$, Overexpression of DREAM specifically inhibited the surface expression of the NR1 subunit without effect on $\mathrm{N}$-cadherin in hippocampal neurons.

ments in CHO cells expressing NMDARs alone or coexpressing DREAM and NMDARs further confirmed the inhibitory effect of DREAM on the surface expression of NMDARs (Fig. 3D). The amount of surface NR1 subunit was reduced in the presence of DREAM $(42.4 \pm 4.0 \%$ of control; $p=0.0048 ; n=3)$. The purity of the surface protein was verified by the absence of $\beta$-actin, which is abundant in the cytoplasm. Thus, when coexpressed with DREAM, a reduction in the density of NMDARs at the cell surface led to a reduction in NMDAR-mediated current.

\section{Neuroprotective effect of DREAM overexpression on neuronal excitotoxic injury}

It is known that excitotoxicity is caused by the overactivation of glutamate receptors, mainly NMDARs, and inhibition of NMDARs can alleviate the neuronal toxicity. We then investigated the effect of DREAM on NMDAR-mediated excitotoxicity 
A

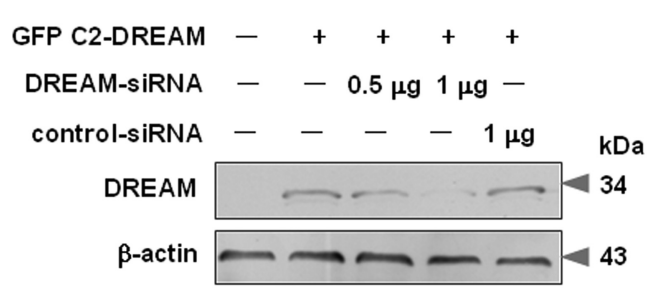

C

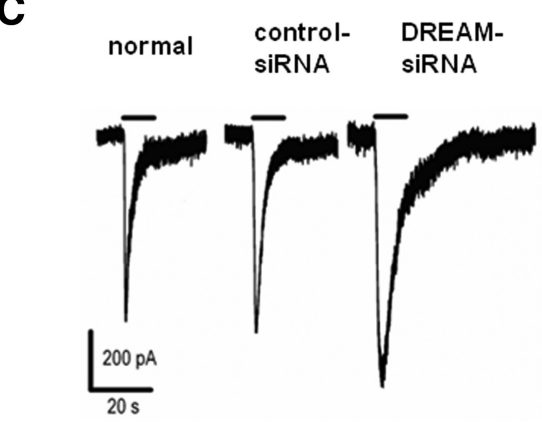

E
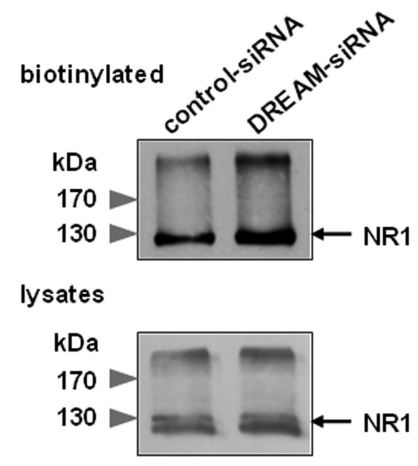

B

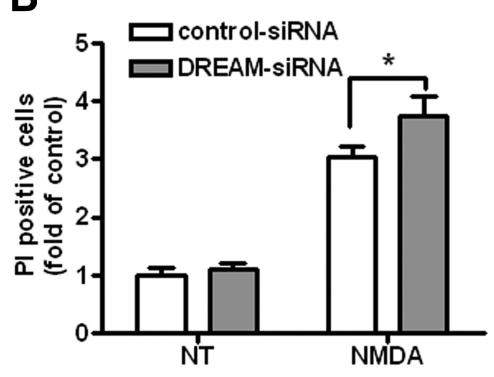

D

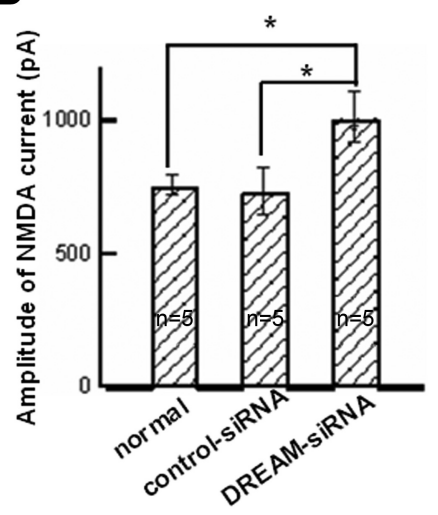

F

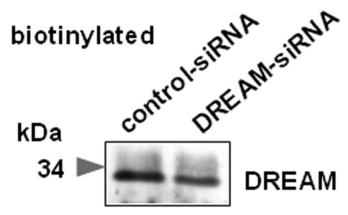

lysates

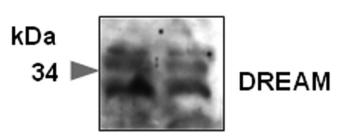

Figure 5. Enhancement of NMDAR-mediated current and excitotoxic injury by DREAM knockdown. $A$, Knockdown of DREAM expression by DREAM siRNA in HEK 293 cells transfected with DREAM plasmids. B, Quantitative analysis of PI-positive cells in hippocampal neurons challenged with NMDA for $1 \mathrm{~h}$, followed by reperfusion for $12 \mathrm{~h}$ after transfection with DREAM siRNA or control siRNA for $24-48 \mathrm{~h}$. DREAM siRNA further exaggerated NMDA-induced neuronal injury. ${ }^{*} p<0.05 ; n=25-35$; two-way ANOVA followed by Bonferroni's posttests. $C$, Representative traces of NMDA-induced current recorded in cultured hippocampal neurons by whole-cell patch clamp. $\boldsymbol{D}$, Quantitative analysis of the peak current amplitude. DREAM siRNA significantly potentiated NMDA-induced current in hippocampal neurons. ${ }^{*} p<0.05 ; n=5$; one-way ANOVA followed by Newman-Keuls posttests. Error bars indicate SEM. $\boldsymbol{E}$, Knockdown of DREAM in hippocampal neurons significantly increased the surface expression of the NR1 subunit without affecting the total amount. $\boldsymbol{F}$, Efficient knockdown of DREAM expression by DREAM siRNA in hippocampal neurons.

in both cell lines transfected with NMDARs and hippocampal neurons.

Administration of $100 \mu \mathrm{M}$ NMDA (plus $10 \mu \mathrm{M}$ glycine) for $2 \mathrm{~h}$ markedly increased the number of PI-positive cells in NMDARtransfected $\mathrm{CHO}$ cells, whereas coexpression of DREAM greatly reduced that (supplemental Fig. S4 $A$, available at www.jneurosci. org as supplemental material). In the control group, $19.2 \pm 1.4 \%$ cells were PI-positive, whereas the percentage of PI-positive cells decreased to $11.9 \pm 2.0 \%(p<0.001)$ in the presence of DREAM (supplemental Fig. S4B, available at www.jneurosci.org as supplemental material), suggesting that DREAM conferred protective effect against NMDA-induced cell death. To further address the functional role of different domains of DREAM on NMDARs, $\mathrm{LDH}$ measurement was performed in $\mathrm{CHO}$ cells cotransfected with NMDARs and GFP or full-length, $\Delta 1-50$, and EF hand mu- tant DREAM, respectively. NMDA treatment for $2 \mathrm{~h}$ induced a $3.7 \pm 0.1$-fold increase in $\mathrm{LDH}$ release in the control group (Fig. 4A). Coexpression of DREAM partially inhibited $\mathrm{LDH}$ leakage by $\sim 21.0 \%(p<0.05$, GFP vs DREAM $)$. $\Delta$ 1-50 DREAM exerted $\sim 38.7 \%$ suppression of LDH release ( $p<0.001$, GFP vs $\Delta$ 1-50 DREAM), indicating that DREAM $\Delta 1-50$ produced better protection than full-length DREAM $(p<0.05$, DREAM vs $\Delta 1-50$ DREAM). It seemed like that the $\mathrm{N}$-terminal 1-50 fragment of DREAM might antagonize the protective role of its core domain containing four EF hand domains. The EF hand mutation of DREAM, however, abolished this effect $(p>0.05$, GFP vs EFmu-DREAM), suggesting that the EF hand domains were required for the inhibitory effect of DREAM on NMDARs.

Next, the cytoprotective effect of DREAM was examined in primary cultured neurons. After adenovirus infection for $48 \mathrm{~h}$, the hippocampal neurons with robust overexpression of DREAM (Fig. $4 B$; supplemental Fig. S4C, available at www.jneurosci. org as supplemental material) were then subjected to $100 \mu \mathrm{M}$ NMDA (plus $10 \mu \mathrm{M}$ glycine) for $1 \mathrm{~h}$, followed by reperfusion with normal medium. Overexpression of DREAM suppressed the NMDA-induced LDH release by $\sim 29.1 \%(p=0.0008)$, $22.3 \%(p=0.0071), 23.3 \%(p=0.0186)$, and $14.7 \%$ after reperfusion for $30 \mathrm{~min}, 2,6$, and $12 \mathrm{~h}$, respectively (Fig. $4 \mathrm{C}$ ). These results show that overexpression of DREAM attenuates NMDAR-mediated excitotoxicity, although it did not reverse NMDAinduced neuronal death.

OGD is commonly used in vitro to mimic ischemia-reperfusion insult of the brain. To avoid severe injury to neurons, we set the OGD treatment time for 30 min. In the control group, OGD treatment induced significant increase of LDH release to $1.9 \pm 0.1-, 2.1 \pm 0.1$-, and $1.9 \pm$ 0.1 -fold after reperfusion for 2, 6, and 12 h, respectively (Fig. 4D). With overexpression of DREAM, however, the same treatment induced a smaller increase in LDH release to $1.4 \pm 0.1(p=0.0008), 1.5 \pm 0.1(p=0.0103)$, and $1.4 \pm 0.1(p=0.0357)$, respectively. In addition, PI staining further confirmed that overexpression of DREAM significantly reduced neuronal death $(60.8 \pm 2.9 \%$ of control; $p<0.001 ; n=29)$ (Fig. $4 E$ ). Together, these results showed the neuroprotective effect of DREAM against ischemia-reperfusion injury in hippocampal neurons.

Consistent with the results in Figure 3, $C$ and D, overexpression of DREAM by infection with recombinant DREAM adenovirus reduced the amount of surface NMDARs (Fig. $4 F$ ). The ratio of surface to total NR1 significantly decreased compared with the control group $(66.0 \pm 6.4 \%$ of control; $p=0.0338 ; n=$ 3 ). In contrast, overexpression of DREAM did not significantly 
alter the surface expression of N-cadherin that served as control. Thus, DREAM overexpression conferred protection against neuronal excitotoxicity injury by reducing the functional NMDARs on the plasma membrane.

Enhancement of NMDAR-mediated current and neuronal excitotoxic injury by DREAM knockdown

To further confirm the neuroprotective effect of DREAM, we then used the siRNA assay. DREAM siRNA could efficiently knockdown the expression of DREAM in transfected HEK 293 cells (Fig. 5A). Then the effect of DREAM siRNA in NMDAinduced current and excitotoxic injury was detected in hippocampal neurons. Wholecell patch-clamp recording showed that, in the control siRNA group, NMDA treatment (100 $\mu \mathrm{m}$ NMDA plus $10 \mu \mathrm{M}$ glycine in the absence of external $\mathrm{Mg}^{2+}$ ) induced an inward current of $734.2 \pm 88.9 \mathrm{pA}$, comparable with that recorded in normal neurons (754.4 \pm 37.5 pA) (Fig. 5C,D). Knockdown of endogenous DREAM with siRNA resulted in potentiation of NMDA current, leading to an increased amplitude at $1010.2 \pm 96.3 \mathrm{pA}(p=0.029)$. DREAM siRNA also significantly exacerbated NMDA-induced cell death in hippocampal neurons. After NMDA exposure, PI-positive cells in DREAM siRNA group increased $\sim 18.5 \%(p<0.05)$ (Fig. $5 B)$ compared with control siRNA. The above data further demonstrated the inhibitory effect of DREAM on NMDAR-mediated current and excitotoxic injury.

Based on the results in Figure $4 F$, we speculated that knockdown of DREAM might upregulate surface expression of the NR1 subunit. As expected, the biotinylation assay in hippocampal neurons showed that transfection of DREAM siRNA significantly increased the surface expression of the NR1 subunit $(133.7 \pm 4.3 \%$ of control; $p=$ $0.0044 ; n=4)$ (Fig. $5 E$ ), without effect on its total amount. Efficient knockdown of DREAM protein either in the total cellular lysates or on the plasma membrane by DREAM siRNA was confirmed (Fig. $5 F$ ). It is worth noting that DREAM protein only showed a single band on the plasma membrane, whereas multiple forms exist in the total lysates. The significance of this finding remains to be determined. Together, knockdown of DREAM enhanced NMDAR-mediated current and neuronal excitotoxic injury by increasing the surface NMDARs.

\section{Generation of the TAT-21-40 fusion peptide and its effect on NMDAR-mediated current}

To further identify the critical binding site in the 1-50 fragment, GST-fusion proteins encoding DREAM-1-20, 11-30, 21-40, and 31-50 were prepared to carry out pull-down studies (Fig. 6A). The results revealed that DREAM-21-40 is the main binding site for the NR1 subunit (Fig. 6B). DREAM-21-40 was rendered cell permeable by fusing it to the protein transduction domain (PTD)
B

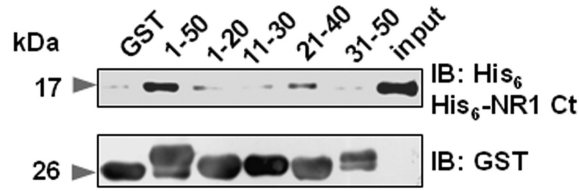

$-31-50$

RIPLSKREGIKWQRPRFTRQ

RKFQEIRQLTIPWSKPRRRG

E

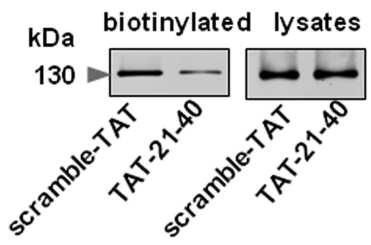

G

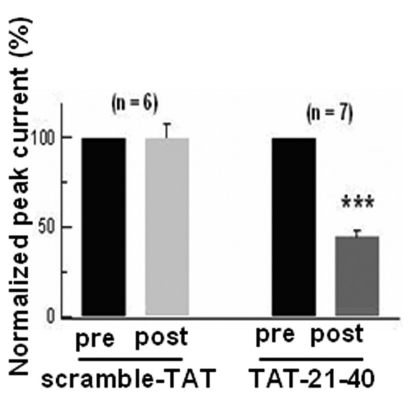

Figure 6. Construction of TAT-21-40 fusion peptide and its effect on NMDAR-mediated current. $\boldsymbol{A}$, Schematic representation of on proteins containing different fragments of DREAM-1-50. B, DREAM 21-40 amino acid residues are the critical binding the binding of GST-1-50 and His - NR1a Ct. TAT-21-40 significantly suppressed the binding of DREAM-1-50 and NR1a C terminus. $\boldsymbol{E}$ hippocampal neurons using whole-cell patch clamp by TAT-fusion peptide pretreatment and posttreatment, respectively. Top, 作 1 min greatly inhibited NMDA-induced current. G, Quantitative analysis of the peak current response in $\boldsymbol{F}$. The values for the posttreatment response were normalized to the corresponding pretreatment values. ${ }^{* * *} p<0.001 ; n=6-7$; two-way ANOVA followed by Bonferroni's posttests. Error bars indicate SEM.

of the HIV-1 transactivator of transcription (TAT) protein. A control peptide was constructed by scrambling the amino acid sequence in DREAM-21-40 (Fig. 6C). Because DREAM-1-50 contains the strongest binding site between DREAM and the NR1 $\mathrm{C}$ terminus, the effect of TAT-21-40 on this binding was examined using GST pull-down studies. The addition of $3 \mu \mathrm{M}$ TAT-21-40 to the reaction buffer significantly reduced the bound $\mathrm{His}_{6}-\mathrm{NR} 1 \mathrm{a}$ Ct $(54.3 \pm 5.7 \%$ of control; $p=0.0152 ; n=3$ ) (Fig. $6 D)$. Moreover, biotinylation assays in hippocampal neurons showed that treatment with $3 \mu \mathrm{M}$ TAT-21-40 for 2 h greatly inhibited surface expression of NR1 ( $44.3 \pm 9.4 \%$ of control; $p=0.0274 ; n=3)$, without affecting its total amount (Fig. 6E).

The effect of the TAT-fusion peptide on NMDAR-mediated current was then directly observed by recording NMDARmediated current both pretreatment and posttreatment with the TAT-fusion peptide in hippocampal neurons. Application of 3 $\mu \mathrm{M}$ scramble-TAT did not change the NMDAR-mediated current (Fig. $6 F$ ). In contrast, application of $3 \mu \mathrm{M}$ TAT-21-40 greatly inhibited the NMDAR-mediated current; the peak current amplitude was reduced to $44.0 \%$ of the pretreatment level $(p<0.001)$ (Fig. 6G). Together, application of TAT-21-40 inhibited NMDAR- 
A

TAT-peptide i.c.v.

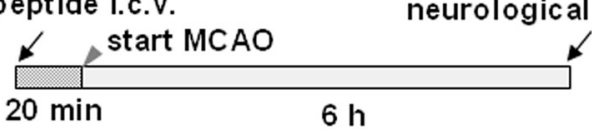

B

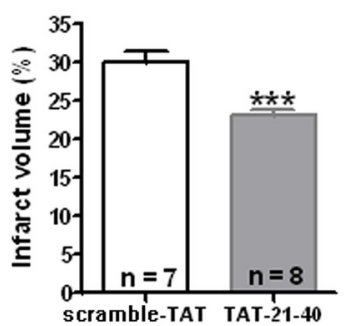

C

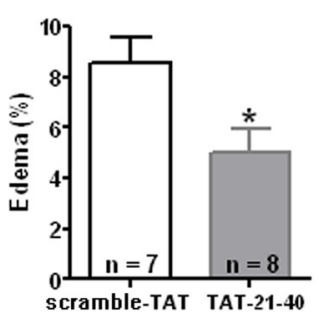

D

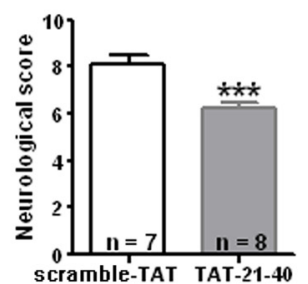

E

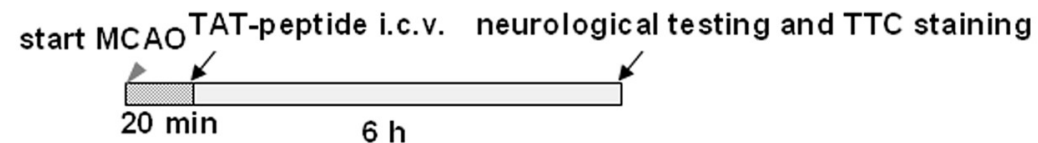

$\mathbf{F}$

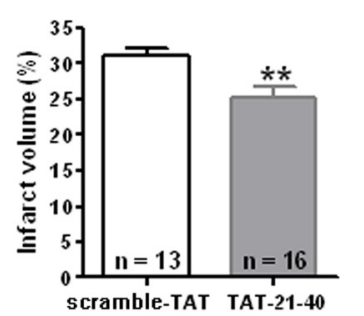

G

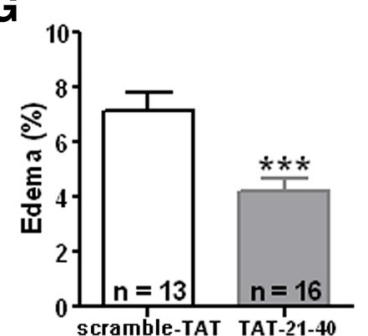

H

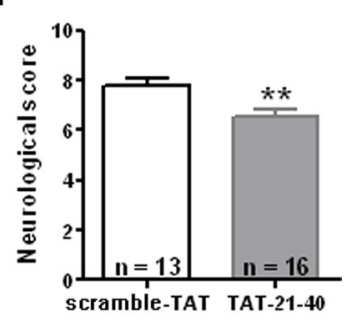

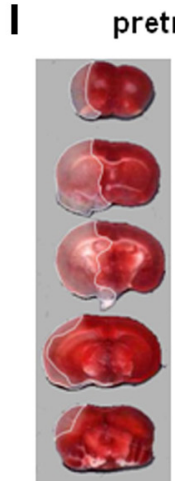

scramble -TAT

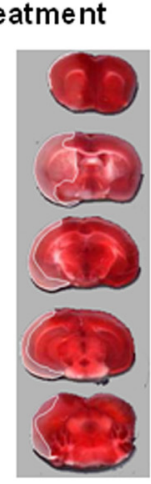

TAT-21 -40

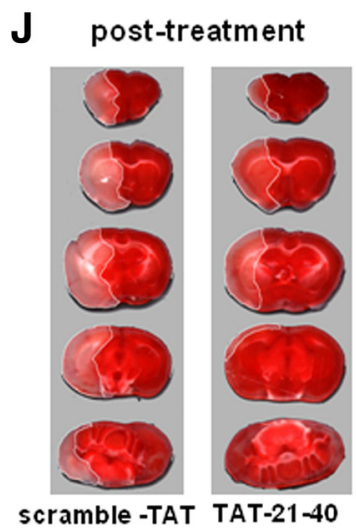

Figure 7. Protection of TAT-21-40 against focal ischemia injury. $\boldsymbol{A}$, Schematic representation of the TAT fusion peptide pretreatment program in vivo. TAT-fusion peptide was administered 20 min before MCA0 through lateral ventricle injection. $\boldsymbol{B}-\boldsymbol{D}$ Pretreatment with TAT-21-40 but not scramble-TAT significantly reduced infarction volume $(\boldsymbol{B})$ and edema $(\boldsymbol{C})$, and improved neurological scores (D) $6 \mathrm{~h}$ after MCA0. ${ }^{*} p<0.05,{ }^{* * *} p<0.001$, unpaired $t$ test. $\boldsymbol{E}$, Schematic representation of the TAT fusion peptide posttreatment program in vivo. TAT-fusion peptide was administered $20 \mathrm{~min}$ after the onset of ischemia through lateral ventricle injection. $\boldsymbol{F}-\boldsymbol{H}$, Posttreatment with TAT-21-40 but not scramble-TAT significantly reduced infarction volume $(\boldsymbol{F})$ and edema $(\boldsymbol{G})$, and improved neurological scores $(\boldsymbol{H}) 6 \mathrm{~h}$ after MCA0 ${ }^{* *} p<0.01,{ }^{* * *} p<0.001$, unpaired $t$ test. Error bars indicate SEM. I,, , Representative photographs of TTC-stained coronal sections of mouse brains by TAT-fusion peptide pretreatment $(I)$ and posttreatment $(J)$. The lines illustrate the infarct border for each section.

mediated current in hippocampal neurons. The significance of this finding was evaluated in the following studies.

\section{Neuroprotective effect of TAT-21-40 on NMDA-induced neuronal injury}

It has been demonstrated that TAT-fusion peptides are efficiently transduced into cells within 30 min (Aarts et al., 2002). To evaluate the effect of TAT-21-40 on neuronal survival, peptides were applied before or after NMDA challenge for $1 \mathrm{~h}$ in hippocampal neurons. Attenuation of NMDA toxicity in cultures treated with TAT-21-40

was prominent compared with cultures treated with control peptides. With pretreatment application (supplemental Fig. S5A, available at www.jneurosci.org as supplemental material), TAT-21-40 (3 $\mu \mathrm{M})$ suppressed NMDA-induced LDH release by $\sim 40.1 \%(p<0.05)$ (supplemental Fig. $\mathrm{S} 5 \mathrm{~B}$, available at www.jneurosci.org as supplemental material). The percentage of PIpositive cells was also reduced by $\sim 33.8 \%$ $(p<0.001)$ after pretreatment of the cultures with TAT-21-40 (supplemental Fig. S5C, available at www.jneurosci.org as supplemental material).

Treatment after the onset of injury would be more valuable and practical in the clinic. After NMDA challenge, $3 \mu \mathrm{M}$ TAT peptide was added to the medium and persisted until the assay for cell damage (supplemental Fig. S5D, available at www. jneurosci.org as supplemental material). The LDH assay showed that TAT-21-40 not only enhanced neuronal viability under normal conditions but also enhanced resistance to NMDA toxicity. After application of TAT-21-40, the basal amount of LDH release was reduced $\sim 66.0 \%(p<0.01)$, whereas NMDA-induced LDH release decreased 10.6\% $(p<0.05)$ (supplemental Fig. S5E, available at www.jneurosci.org as supplemental material). The percentage of PI-positive cells was also reduced $\sim 17.8 \%$ $(p<0.001)$ with application of TAT-21-40 after the insult (supplemental Fig. S5F, available at www.jneurosci.org as supplemental material). Together, the above data revealed the neuroprotective effects of the cell-permeable peptide TAT-21-40.

\section{Neuroprotective effect of TAT-21-40 against focal cerebral ischemia}

As neuronal death in cerebral ischemia is primarily attributable to excitotoxic mechanisms, we further tested the effect of TAT-fusion peptide in permanent MCAO model in mice. Occlusion of the left middle cerebral artery resulted in a major infarction predominantly in the cortex and striatum, and produced severe behavioral deficits in mice. Since the brain volumes of mice were somewhat variable, we expressed the lesions as a percentage of the volume of the cerebral hemisphere. TAT-21-40 pretreatment $(2 \mu \mathrm{g} / \mathrm{ml} ; 2.5 \mu \mathrm{l}) 20 \mathrm{~min}$ before MCAO through ipsilateral intracerebroventrical injection (Fig. 7A) significantly decreased the infarct volume by $22.9 \%(p=0.0002)$ (Fig. $7 B, I)$ and reduced the edema by $41.4 \%(p=0.0205)$ (Fig. $7 C)$. Neurological outcome measurements were also performed. TAT-21-40-pretreated animals showed improved neurological scores compared with control ( $p=0.0005)$ (Fig. $7 D)$.

An ischemia treatment would be more therapeutically valuable if effective when given after the onset of ischemia. As the 
glutamate receptor activation and $\mathrm{Ca}^{2+}$ entry occur very early, we applied the TAT-fusion peptide on the early phase of ischemia. The results showed that administration of TAT-21-40 $20 \mathrm{~min}$ after the insult (Fig. 7E) was still protective, decreasing the infarct volume by $18.8 \%$ $(p=0.0032)$ (Fig. $7 F, J)$ and reducing edema by $40.7 \%(p=0.0007)$ (Fig. $7 G)$. Behavioral deficits in mice was also attenuated by TAT-21-40 administered $20 \mathrm{~min}$ after the onset of the ischemia ( $p=$ 0.0039) (Fig. $7 H$ ). Together, TAT-21-40 either pretreatment or posttreatment exhibited the neuroprotective effect against focal cerebral ischemia, significantly decreasing infarct volume, reducing edema and improving behavioral outcome.

\section{Discussion}

Given the essential roles of NMDARs in synaptic plasticity and excitotoxicity, studying their regulatory mechanisms is of great significance. The current studies provide the first evidence that the multifunctional protein DREAM behaves as a negative modulator of NMDARs through direct interaction with the NR1 subunit. So far, a number of NR1 or NR2 subunit binding partners have been identified in the postsynaptic density. The NR1 binding pro-

teins include calmodulin (CaM) (Ehlers et al., 1996; Akyol et al., 2004), CaMKII (Leonard et al., 2002), $\alpha$-actinin (Wyszynski et al., 1997; Merrill et al., 2007), tubulin (van Rossum et al., 1999), spectrin (Wechsler and Teichberg, 1998), and neurofilament (Ehlers et al., 1998) and Yotiao (Lin et al., 1998). Here, we identify a new binding partner of the NR1 subunit, DREAM.

A prominent role of the binding partners of NMDARs is coupling the receptors to intracellular proteins and signaling enzymes. For example, the interactions of CaM and $\alpha$-actinin with the NR1 subunit have been documented to modulate $\mathrm{Ca}^{2+}$-dependent inactivation (CDI) of NMDARs (Ehlers et al., 1996; Krupp et al., 1999), which serves as a negative-feedback control system to regulate channel gating. Other scaffold proteins play critical roles in the anchoring or clustering of NMDARs. Here, we show that DREAM also associates with the NR1 subunit in a $\mathrm{Ca}^{2+}$-dependent manner. The DREAM-NR1 interaction was enhanced in the presence of $\mathrm{Ca}^{2+}$ (Fig. $1 E, F$ ). Taking into account the inhibitory effects of DREAM on NMDARs, we hypothesize that DREAM might be another $\mathrm{Ca}^{2+}$-sensitive regulator for negative-feedback control of NMDARs. The hypothesis is as follows (Fig. 8). In the resting state, a few DREAM molecules bind to the $\mathrm{C} 0$ domain of the NR1 subunit. On activation of NMDARs, $\mathrm{Ca}^{2+}$ influx enhances the DREAMNR1 interaction, causing reduced surface expression of NMDARs. Because it has been generally acknowledged that excessive activation of NMDARs leads to excitotoxicity by inducing $\mathrm{Ca}^{2+}$ overload, suppression of available functional NMDARs on the cell surface may alleviate excitotoxic injury. Thus, DREAM may confer protection against excitotoxic injury by the inhibition of NMDARs. Because NCS proteins exhibit higher affinity for $\mathrm{Ca}^{2+}$ than $\mathrm{CaM}$ (Burgoyne, 2004), DREAM could perform a regulatory role for NMDARs at lower intracellular $\mathrm{Ca}^{2+}$ concentration and cooperate with CaM to fulfill function of the negative-feedback control of NMDARs.

In investigating possible mechanisms underlying the inhibitory effects of DREAM on NMDARs, we found that coexpression or overexpression of DREAM significantly reduced the number of NMDARs on the cell surface. Because the balance between trafficking and endocytosis determines the final number of NMDARs on the cell surface, DREAM might regulate the surface expression of NMDARs by either promoting their endocytosis or preventing their surface delivery. DREAM is a member of NCS family, which is divided into five subfamilies: recoverins, guanylate cyclase activating proteins (GCAPs), frequenin (NCS-1), visinin-like protein (VSNL), and KChIP (Burgoyne, 2007). A general role for NCS proteins in membrane transport and receptor trafficking is supported by a variety of studies (Weiss et al., 2000; Lin et al., 2002; Brackmann et al., 2005; Haynes et al., 2005; Palmer et al., 2005), and direct interactions have been revealed between NCS proteins and molecules involved in membrane trafficking (Ivings et al., 2002; Palmer et al., 2005). It has been reported that visinin-like protein 1 (VILIP-1) and VILIP-3 form a complex with the GluR6 subunit of kainite receptors (Coussen et al., 2005), although the functional effect of this complex is unknown. Moreover, binding of VILIP proteins to GluR6 was dramatically reduced in the absence of $\mathrm{Ca}^{2+}$, similar to the DREAM-NR1 interaction. Another NCS protein, hippocalcin, acts as a $\mathrm{Ca}^{2+}$ sensor for AMPA receptor endocytic trafficking during long-term depression (Palmer et al., 2005). Additional studies are needed to elucidate the regulatory mechanisms of DREAM on NMDARs in detail.

The binding site between DREAM and NR1a was determined by in vitro studies. The binding site in the NR1 subunit is located in the C0 domain, which is common to the eight splice variants of the 
NR1 subunit, suggesting the possibility that DREAM might associate with the other NR1 splicing variants. The $\mathrm{C} 0$ domain contains two endocytic signals, tyrosine-based YKRH and lysine-based VWRK, which contribute to the endocytosis of NMDARs independent of NR2 subunits (Scott et al., 2004). The C0 domain also serves as a docking site for activated CaMKII (Leonard et al., 2002). In addition, the $\mathrm{C} 0$ domain plays a critical role in coordinating $\mathrm{Ca}^{2+}$ signaling and cytoskeletal association and is required for CDI and the downstream signaling pathways of NMDARs such as activation of the ERK-CREB (extracellular signal-regulated kinase-cAMP response element-binding protein) pathway (Bradley et al., 2006). In brief, the $\mathrm{C} 0$ domain may act as an "integrator" of diverse cellular signals, the readout of which is both NMDAR channel function and number. The DREAM-NR1 interaction might be involved in the regulation of these processes.

With regard to DREAM, two regions can bind NR1: the highaffinity $\mathrm{N}$-terminal 1-50 residues and the low-affinity middle and $\mathrm{C}$ terminus. The $\mathrm{N}$ terminus of KChIPs shows very high diversity, whereas the $\mathrm{C}$ terminus is conserved, containing four EF hand domains or core domains. Whether there are interactions between KChIP1, 2, or 4 and the NR1 subunit needs to be studied further. It is noteworthy that DREAM is a substrate for caspase-3 cleavage, which would result in the production of a small ( $\sim 60$ aa) N-terminal fragment and a larger C-terminal fragment (Choi et al., 2003). Recently, it was reported that the N-terminal region of DREAM containing the first 90 aa is required for DREAM-TSHR (thyroid-stimulating hormone receptor) interaction (Rivas et al., 2009). Thus, the $\mathrm{N}$ terminus of DREAM plays a critical role in the association of DREAM and its binding partners.

The role of EF hand domains in the DREAM-NR1 interaction is dual. EF hand mutation abolished the inhibitory effect of DREAM on NMDA receptor-mediated excitotoxicity with no effect on the association between DREAM and NR1. It appears that the EF hand domains are dispensable for DREAM-NR1 association but essential for the $\mathrm{Ca}^{2+}$ sensitivity of this association and its functional consequences. Indeed, in the case of KChIP1Kv4 interaction, binding tolerates EF hand mutation, whereas modulation of Kv4.2 kinetics and traffic by KChIP1 is dependent on the EF hand domains (Flowerdew and Burgoyne, 2009).

This study showed that DREAM N-terminal 1-50 residues might antagonize the function of the DREAM core domain (Fig. $4 A)$. Similarly, the N-terminal KIS ( $\mathrm{K}^{+}$channel inactivation suppressor) domain of KChIP4a prevents core domain-mediated regulation of $\mathrm{Kv} 4$ channel properties (Jerng and Pfaffinger, 2008). Furthermore, we identified that the amino acids $21-40$ of DREAM in the $\mathrm{N}$ terminus is the main binding site for the NR1 subunit; thus, application of amino acids 21-40 of DREAM might relieve the autoinhibition conferred by DREAM 1-50 and derepress the DREAM core domain by a competitive mechanism.

Recently, the use of TAT-fusion peptides as an approach for in vivo application has attracted much attention. The PTD sequence of TAT allows the conjugated peptide effectively to penetrate across the plasma membrane of various cells, as well as across the blood-brain barrier and efficiently into neurons in vivo. It has been shown that a TAT-fusion peptide comprising the nine C-terminal residues of the NR2B subunit can alleviate rat ischemic injury by perturbing the interactions between NMDARs and PSD95 (Aarts et al., 2002). Our results showed that cell-permeable TAT-21-40 peptides have a neuroprotective effect on in vitro excitotoxicity and in vivo ischemic brain damage. Moreover, both pretreatment and posttreatment of TAT-21-40 confer protection against excitotoxic injury. Thus, TAT21-40 could be a promising therapeutic approach for the clinical treatment of excitotoxicity-related disease.
In this study, we focused on the DREAM-NR1 interaction and selectively studied NR1 and NR2B recombinant NMDARs in a heterologous expression system, given that it has been generally accepted that NMDA-mediated excitotoxicity is caused mainly by the activation of NR2B- but not NR2A-containing NMDARs (Zhou and Baudry, 2006; Liu et al., 2007). However, the interactions between DREAM and NR2 subunits (supplemental Fig. $\mathrm{S} 1 B, C$, available at www.jneurosci.org as supplemental material) and the subsequent functional effect should be considered. We cannot rule out the contribution of DREAM-NR2 interaction to the inhibitory effect of DREAM to NMDARs. Additional studies are needed to address this issue.

The functions of NCS proteins have begun to emerge in recent years. Despite their sequence and structural similarities, the functional diversity of NCS proteins is clear, including the regulation of phototransduction, neurotransmission, $\mathrm{Ca}^{2+}$ and $\mathrm{Kv} 4$ channel function, dopamine receptor internalization, and trafficking of nicotinic receptors. The identification of the novel function of DREAM, a modulator of NMDARs, undoubtedly provides new insights into the multifunctional properties of DREAM and NCS family members. Similar to the prototypical $\mathrm{Ca}^{2+}$ sensor CaM, DREAM appears to be a modulator of multiple intracellular targets, showing pleiotropic actions. Most important, because clinical trials with NMDAR antagonists have been discouraging, a better understanding of the regulatory mechanisms of NMDARs will facilitate a breakthrough in this field. The DREAM-NR1 interaction offers a potential target for the prevention and control of NMDAR-mediated excitotoxic injury.

\section{References}

Aarts M, Liu Y, Liu L, Besshoh S, Arundine M, Gurd JW, Wang YT, Salter MW, Tymianski M (2002) Treatment of ischemic brain damage by perturbing NMDA receptor-PSD-95 protein interactions. Science 298:846-850.

Akyol Z, Bartos JA, Merrill MA, Faga LA, Jaren OR, Shea MA, Hell JW (2004) Apo-calmodulin binds with its C-terminal domain to the $N$-methyl-Daspartate receptor NR1 C0 region. J Biol Chem 279:2166-2175.

Alexander JC, McDermott CM, Tunur T, Rands V, Stelly C, Karhson D, Bowlby MR, An WF, Sweatt JD, Schrader LA (2009) The role of calsenilin/DREAM/ KChIP3 in contextual fear conditioning. Learn Mem 16:167-177.

An WF, Bowlby MR, Betty M, Cao J, Ling HP, Mendoza G, Hinson JW, Mattsson KI, Strassle BW, Trimmer JS, Rhodes KJ (2000) Modulation of A-type potassium channels by a family of calcium sensors. Nature 403:553-556.

Brackmann M, Schuchmann S, Anand R, Braunewell KH (2005) Neuronal $\mathrm{Ca}^{2+}$ sensor protein VILIP-1 affects cGMP signalling of guanylyl cyclase $\mathrm{B}$ by regulating clathrin-dependent receptor recycling in hippocampal neurons. J Cell Sci 118:2495-2505.

Bradley J, Carter SR, Rao VR, Wang J, Finkbeiner S (2006) Splice variants of the NR1 subunit differentially induce NMDA receptor-dependent gene expression. J Neurosci 26:1065-1076.

Burgoyne RD (2004) The neuronal calcium-sensor proteins. Biochim Biophys Acta 1742:59-68.

Burgoyne RD (2007) Neuronal calcium sensor proteins: generating diversity in neuronal $\mathrm{Ca}^{2+}$ signalling. Nat Rev Neurosci 8:182-193.

Buxbaum JD, Choi EK, Luo Y, Lilliehook C, Crowley AC, Merriam DE, Wasco W (1998) Calsenilin: a calcium-binding protein that interacts with the presenilins and regulates the levels of a presenilin fragment. Nat Med 4:1177-1181.

Carrión AM, Link WA, Ledo F, Mellström B, Naranjo JR (1999) DREAM is $\mathrm{a} \mathrm{Ca}^{2+}$-regulated transcriptional repressor. Nature 398:80-84.

Cheng HY, Pitcher GM, Laviolette SR, Whishaw IQ, Tong KI, Kockeritz LK, Wada T, Joza NA, Crackower M, Goncalves J, Sarosi I, Woodgett JR, Oliveira-dos-Santos AJ, Ikura M, van der Kooy D, Salter MW, Penninger JM (2002) DREAM is a critical transcriptional repressor for pain modulation. Cell 108:31-43.

Choi DW, Koh JY, Peters S (1988) Pharmacology of glutamate neurotoxic- 
ity in cortical cell culture: attenuation by NMDA antagonists. J Neurosci 8:185-196.

Choi EK, Miller JS, Zaidi NF, Salih E, Buxbaum JD, Wasco W (2003) Phosphorylation of calsenilin at Ser63 regulates its cleavage by caspase-3. Mol Cell Neurosci 23:495-506.

Coussen F, Perrais D, Jaskolski F, Sachidhanandam S, Normand E, Bockaert J, Marin P, Mulle C (2005) Co-assembly of two GluR6 kainate receptor splice variants within a functional protein complex. Neuron 47:555-566.

D’Andrea B, Di Palma T, Mascia A, Motti ML, Viglietto G, Nitsch L, Zannini M (2005) The transcriptional repressor DREAM is involved in thyroid gene expression. Exp Cell Res 305:166-178.

Ehlers MD, Zhang S, Bernhadt JP, Huganir RL (1996) Inactivation of NMDA receptors by direct interaction of calmodulin with the NR1 subunit. Cell 84:745-755.

Ehlers MD, Fung ET, O’Brien RJ, Huganir RL (1998) Splice variant-specific interaction of the NMDA receptor subunit NR1 with neuronal intermediate filaments. J Neurosci 18:720-730.

Flowerdew SE, Burgoyne RD (2009) A VAMP7/Vtila SNARE complex distinguishes a non-conventional traffic route to the cell surface used by KChIP1 and Kv4 potassium channels. Biochem J 418:529-540.

Fontán-Lozano A, Romero-Granados R, del-Pozo-Martín Y, Suárez-Pereira I, Delgado-García JM, Penninger JM, Carrión AM (2009) Lack of DREAM protein enhances learning and memory and slows brain aging. Curr Biol 19:54-60.

Gomez-Villafuertes R, Torres B, Barrio J, Savignac M, Gabellini N, Rizzato F, Pintado B, Gutierrez-Adan A, Mellström B, Carafoli E, Naranjo JR (2005) Downstream regulatory element antagonist modulator regulates $\mathrm{Ca}^{2+}$ homeostasis and viability in cerebellar neurons. J Neurosci 25:10822-10830.

Haynes LP, Thomas GM, Burgoyne RD (2005) Interaction of neuronal calcium sensor-1 and ADP-ribosylation factor 1 allows bidirectional control of phosphatidylinositol 4-kinase beta and trans-Golgi network-plasma membrane traffic. J Biol Chem 280:6047-6054.

Ivings L, Pennington SR, Jenkins R, Weiss JL, Burgoyne RD (2002) Identification of $\mathrm{Ca}^{2+}$-dependent binding partners for the neuronal calcium sensor protein neurocalcin delta: interaction with actin, clathrin and tubulin. Biochem J 363:599-608.

Jerng HH, Pfaffinger PJ (2008) Multiple Kv channel-interacting proteins contain an $\mathrm{N}$-terminal transmembrane domain that regulates Kv4 channel trafficking and gating. J Biol Chem 283:36046-36059.

Krupp JJ, Vissel B, Thomas CG, Heinemann SF, Westbrook GL (1999) Interactions of calmodulin and alpha-actinin with the NR1 subunit modulate $\mathrm{Ca}^{2+}$-dependent inactivation of NMDA receptors. J Neurosci 19:1165-1178.

Leonard AS, Lim IA, Hemsworth DE, Horne MC, Hell JW (1999) Calcium/ calmodulin-dependent protein kinase II is associated with the $\mathrm{N}$-methylD-aspartate receptor. Proc Natl Acad Sci U S A 96:3239-3244.

Leonard AS, Bayer KU, Merrill MA, Lim IA, Shea MA, Schulman H, Hell JW (2002) Regulation of calcium/calmodulin-dependent protein kinase II docking to $N$-methyl-D-aspartate receptors by calcium/calmodulin and alpha-actinin. J Biol Chem 277:48441-48448.

Lilliehook C, Bozdagi O, Yao J, Gomez-Ramirez M, Zaidi NF, Wasco W, Gandy S, Santucci AC, Haroutunian V, Huntley GW, Buxbaum JD (2003) Altered $A \beta$ formation and long-term potentiation in a calsenilin knock-out. J Neurosci 23:9097-9106.

Lin JW, Wyszynski M, Madhavan R, Sealock R, Kim JU, Sheng M (1998) Yotiao, a novel protein of neuromuscular junction and brain that interacts with specific splice variants of NMDA receptor subunit NR1. J Neurosci 18:2017-2027.

Lin L, Jeanclos EM, Treuil M, Braunewell KH, Gundelfinger ED, Anand R
(2002) The calcium sensor protein visinin-like protein-1 modulates the surface expression and agonist sensitivity of the $\alpha 4 \beta 2$ nicotinic acetylcholine receptor. J Biol Chem 277:41872-41878.

Link WA, Ledo F, Torres B, Palczewska M, Madsen TM, Savignac M, Albar JP, Mellström B, Naranjo JR (2004) Day-night changes in downstream regulatory element antagonist modulator/potassium channel interacting protein activity contribute to circadian gene expression in pineal gland. J Neurosci 24:5346-5355.

Liu Y, Wong TP, Aarts M, Rooyakkers A, Liu L, Lai TW, Wu DC, Lu J, Tymianski M, Craig AM, Wang YT (2007) NMDA receptor subunits have differential roles in mediating excitotoxic neuronal death both in vitro and in vivo. J Neurosci 27:2846-2857.

Mayanagi K, Katakam PV, Gáspár T, Domoki F, Busija DW (2008) Acute treatment with rosuvastatin protects insulin resistant $(\mathrm{C} 57 \mathrm{BL} / 6 \mathrm{~J} \mathrm{ob} / \mathrm{ob})$ mice against transient cerebral ischemia. J Cereb Blood Flow Metab 28:1927-1935.

Merrill MA, Malik Z, Akyol Z, Bartos JA, Leonard AS, Hudmon A, Shea MA, Hell JW (2007) Displacement of alpha-actinin from the NMDA receptor NR1 C0 domain by $\mathrm{Ca}^{2+} /$ calmodulin promotes CaMKII binding. Biochemistry 46:8485-8497.

Palmer CL, Lim W, Hastie PG, Toward M, Korolchuk VI, Burbidge SA, Banting G, Collingridge GL, Isaac JT, Henley JM (2005) Hippocalcin functions as a calcium sensor in hippocampal LTD. Neuron 47:487-494.

Rivas M, Mellström B, Torres B, Cali G, Ferrara AM, Terracciano D, Zannini M, Morreale de Escobar G, Naranjo JR (2009) The DREAM protein is associated with thyroid enlargement and nodular development. Mol Endocrinol 23:862-870.

Rodriguez R, Santiago-Mejia J, Gomez C, San-Juan ER (2005) A simplified procedure for the quantitative measurement of neurological deficits after forebrain ischemia in mice. J Neurosci Methods 147:22-28.

Sanz C, Mellstrom B, Link WA, Naranjo JR, Fernandez-Luna JL (2001) Interleukin 3-dependent activation of DREAM is involved in transcriptional silencing of the apoptotic Hrk gene in hematopoietic progenitor cells. EMBO J 20:2286-2292.

Sattler R, Tymianski M (2001) Molecular mechanisms of glutamate receptormediated excitotoxic neuronal cell death. Mol Neurobiol 24:107-129.

Savignac M, Pintado B, Gutierrez-Adan A, Palczewska M, Mellström B, Naranjo JR (2005) Transcriptional repressor DREAM regulates T-lymphocyte proliferation and cytokine gene expression. EMBO J 24:3555-3564.

Scott DB, Michailidis I, Mu Y, Logothetis D, Ehlers MD (2004) Endocytosis and degradative sorting of NMDA receptors by conserved membraneproximal signals. J Neurosci 24:7096-7109.

van Rossum D, Kuhse J, Betz H (1999) Dynamic interaction between soluble tubulin and C-terminal domains of $N$-methyl-D-aspartate receptor subunits. J Neurochem 72:962-973.

Wechsler A, Teichberg VI (1998) Brain spectrin binding to the NMDA receptor is regulated by phosphorylation, calcium and calmodulin. EMBO J 17:3931-3939.

Weiss JL, Archer DA, Burgoyne RD (2000) Neuronal $\mathrm{Ca}^{2+}$ sensor-1/frequenin functions in an autocrine pathway regulating $\mathrm{Ca}^{2+}$ channels in bovine adrenal chromaffin cells. J Biol Chem 275:40082-40087.

Wexler EJ, Peters EE, Gonzales A, Gonzales ML, Slee AM, Kerr JS (2002) An objective procedure for ischemic area evaluation of the stroke intraluminal thread model in the mouse and rat. J Neurosci Methods 113:51-58.

Wyszynski M, Lin J, Rao A, Nigh E, Beggs AH, Craig AM, Sheng M (1997) Competitive binding of alpha-actinin and calmodulin to the NMDA receptor. Nature 385:439-442.

Zhou M, Baudry M (2006) Developmental changes in NMDA neurotoxicity reflect developmental changes in subunit composition of NMDA receptors. J Neurosci 26:2956-2963. 